\title{
Ценности здорового образа жизни: медийные практики продвижения
}

(на примере массовой прессы)

Елизавета Стрига

В статье представлены результаты контент-анализа массовой периодической печати России, проведенного в 2018-2019 гг. с целью оценки практик продвижения здорового образа жизни и выявления ресурсов повышения их потенциальной эффективности. Автор комментирует достижения и просчеты газетных изданий в контексте представлений о здоровье как гуманитарной ценности и его воздействии на национальное развитие.

Ключевые слова: ценности 30Ж, массовая пресса, аудитория, медиапрактики, контент-анализ.
(C) Стрига Елизавета Андреевна

аспирантка кафедры периодической печати факультета журналистики

МГУ имени М.В. Ломоносова

(г. Москва, Россия), striga_elizaveta@mail.ru
Здоровье, здравоохранение, здоровый образ жизни (ЗОЖ) - одна из наиболее популярных тем массовой периодической печати. Насколько качество этих публикаций соответствует потребностям аудитории? Как используют СМИ свой медийный потенциал для вовлечения широких масс населения в здоровьесберегающие практики повседневности? Исследование контента массовых газет позволило выявить некоторые особенности данного содержательного сегмента.

\section{Концепции здорового образа жизни и возможности СМИ}

Проблемный контекст, определяющий актуальность анализа медийных практик (целей, тематики, жанров и других аспектов продвижения ценностей 30Ж) в периодической печати России, состоит в следующем: средняя продолжительность жизни в России в 2018 г. составляла 67 лет для мужчин и 77 - для женщин, в то время как аналогичный показатель по Евросоюзу составляет 78 лет для мужчин и 83 года для женщин ${ }^{1}$. Россия стоит перед лицом серьезных рисков в сфере здоровья населения и, как следствие, экономического и духовного развития страны². Отрадно констатировать, что в соответствии с индексом человеческого развития (ИЧР), который 
является комплексным сравнительным показателем ожидаемой продолжительности жизни, грамотности, образования и уровня жизни для стран во всем мире, Россия среди 193 стран мира занимает 49 место $^{3}$. Этот показатель медленно повышается, Россия входит в число стран с «высоким уровнем развития» (по показателям здоровья два десятилетия назад у России было 134 место), но едва ли мы можем быть удовлетворены настоящим положением дел. На рост продолжительности жизни, улучшение качества жизни во всех половозрастных группах населения направлен один из приоритетных национальных проектов "Демография»4, назначение которого состоит в преодолении сложившейся ситуации и повышении показателей здоровья россиян.

В концепциях социальной политики и здоровьесбережения, наряду с развитием здравоохранения и медицины, ведущее место отводится здоровому образу жизни населения, его идеологии и практике. «Увеличение числа граждан, в том числе пожилого и старческого возраста, приверженных здоровому образу жизни и принципам здорового, активного долголетия, создание для этого необходимых условий, снижение факторов среды обитания, негативно влияющих на здоровье, а также коррекция поведенческих факторов риска <...> приводят к снижению смертности населения» 5 .

30Ж имеет множество определений. Выделим основные из них: это поведение и мышление человека, обеспечивающие ему охрану и укрепление здоровья; индивидуальная система привычек, которая дает человеку необходимый уровень жизнедеятельности для решения задач, связанных с выполнением обязанностей и для решения личных проблем и запросов; система жизни, поддерживающая достаточный и оптимальный обмен человека со средой и тем самым позволяющая со- хранить здоровье на безопасном уровнеб; совокупность личных и социальных практик сохранения здоровья (Рагимова, 2012: 15); единство всех видов индивидуальной и социальной человеческой деятельности, а также природных, социальных и культурных условий, обеспечивающих достижение максимально возможного физического, духовного, социального развития человека (Афанасьева, Воробьев, 2013: 85); совокупность сформированных в процессе социализации мотивов, установок и убеждений, которые способствуют сохранению и укреплению физического, психического и социального здоровья (Гиппократ, 1998: $111)$; активность личности, группы людей, общества, использующих материальные и духовные условия и возможности в интересах здоровья, гармонического физического и духовного развития человека (Лисицын, Сахно, 2008: 7); последовательная стратегия постоянного уменьшения рисков для здоровья (Быховская, 2000: 86); способ самоидентификации, показатель принадлежности к определенному социальному сообществу (Розин, 2000: 36); следование идеалу гражданина - поддерживать честь страны, местности, профессионального сообщества (Гурвич, 1997: 26).

В совокупности данных определений нашли выражение философия здоровья как личной и общественной ценности, ценностно-психологические установки, обозначение условий, необходимых для повышения качества жизни, наполнение конкретным смыслом действий, входящих в 30Ж. Мы определяем 30Ж как единство всех видов индивидуальной и социальной деятельности человека в среде экономических, социальных, культурных и природных условий с целью достижения максимально возможного физического, социального и духовного развития человека (Стрига, 2018: 158).

Идеология образа жизни в теоретических работах подробно исследована (Магидов, 
2010; Сорокина, Сорокин, 2009; Страхова, 2005). Однако в реальности ситуация достаточно сложная. По мнению экспертов (Бриленок, 2016: 5), доминирующими факторами, сокращающими жизненный путь россиян, снижающими качество жизни являются: неблагоприятная экологическая среда обитания, вредные привычки, устоявшиеся семейные традиции, придание чрезмерного значения телевидению, агрессивность, низкий уровень доходов, гиподинамия, недостаточное количество доступных спортивных сооружений (стадионов, бассейнов, спортивных залов) и дороговизна их посещения, низкий статус здорового образа жизни в системе ценностей семьи и общества, а потому и отсутствие мотивации к ведению 30Ж. В частности, по данным Минздрава, «до 70\% смертей российских мужчин трудоспособного возраста вызваны употреблением алкоголя. Как сообщила министр здравоохранения Вероника Скворцова [занимала этот пост до отставки Правительства РФ в январе 2020 г. - E.C.], в настоящее время мужская смертность в России в несколько раз превышает показатель Европы»7.

В среде молодежи дополнительными факторами являются зависимость от соци альных сетей и компьютерных игр, неблагоприятное влияние молодежных групп, раннее асоциальное поведение, деструктивные субкультуры. Вследствие этих причин значительная часть населения России не смогла сделать выбор в пользу ЗОЖ и, следовательно, не решила задачу повышения качества жизни и активной старости, а также проблему преждевременной смертности 8 .

Определенную роль в данной проблемной ситуации играет также недостаточная информированность населения о возможностях и достоинствах 30Ж. В обозначенном контексте задачи СМИ определяются нами как необходимость применения научных, психологически обоснованных ме- тодик продвижения ценностей 3ОЖ среди населения России, содействие необходимости создания системы целенаправленного, научно обоснованного подхода к убеждению людей в ценностях 30Ж, которые и раскрывают путь к здоровью и долголетию человека, материальному и духовному благополучию семей, творческой самореализации личности.

\section{Практики массовых газет в продвижении 30Ж: результаты исследования}

Массовая периодическая печать (Шкондин, Реснянская (ред.), 2009: 236) как объект изучения в данном контексте представляет особый интерес: она ориентирована на массового читателя, имеет простой и доходчивый стиль изложения, дает практические советы в различных сферах повседневной жизни, что и обусловливает большие тиражи и широкую аудиторию этих изданий и, как следствие, их коммерческий успех (Фролова, 2014: 352).

В формировании программы исследования мы опирались на ранее осуществленные труды, в которых обозначались место (Гавриченкова, 2018), роль (Пилипцев, Часнойть, Павлович, 2016) и задачи (Калина, 2014) СМИ в привлечении населения России к 30Ж. Эти работы помогли нам понять, какие содержательно-формальные установки наиболее важны для понимания эффективности медийных практик.

В качестве объекта исследования были определены газеты «Московский комсомолец» и «Аргументы и факты» как наиболее типичные представители массовой прессы. Период исследования - c 1 мая 2018 г. по 30 апреля 2019 г., т.е. один год. По запросу «здоровый образ жизни» было выделено 587 публикаций, составивших сплошную выборку исследования. Использовался метод классического контент-анализа. Выделение категорий анализа (целевые ориентиры, тематика, жанры, субъекты мнений, 
характер аргументации) отражало наше намерение получить развернутую информацию о практиках газет, сопоставить их задачи и дать оценку этим практикам с позиций потенциальной эффективности. Результаты подсчетов систематизированы и представлены в таблицах.

В определении целей (назначения) мы рассматривали варианты общей направленности публикаций: информационная изложение фактов в нейтральном ключе, без поясняющих комментариев и мнений участников события; просветительская - публикация рассказывает читателю о конкретных мерах следования 30ж; рекламная в материале представлены мероприятия, процедуры, товары, продукты, поддерживающие 30ж; мотивационная - публикация способствует привлечению читателя к участию в организуемых мероприятиях, мотивирует к следованию определенным рекомендациям врачей, психологов, педагогов, кулинаров, воздержанию от не соответствующих 30Ж привычек (см. табл. 1).

Таблица 1. Назначение публикаций

\begin{tabular}{|c|l|c|c|}
\hline № & \multicolumn{1}{|c|}{ Цель } & Количество & \% \\
\hline 1 & Информационная & 313 & 53,4 \\
\hline 2 & Просветительская & 118 & 20,1 \\
\hline 3 & Рекламная & 59 & 10 \\
\hline 4 & Мотивационная & 94 & 16 \\
\hline 5 & Другое & 3 & 0,5 \\
\hline \multicolumn{2}{|c|}{ Итого } & 587 & 100 \\
\hline
\end{tabular}

Анализ публикаций показал: что 53,4\% публикаций - информационные. В них присутствует ключевое словосочетание «здоровый образ жизни», но по факту они не отражают его смысловое наполнение и не выполняют ни мотивационную, ни образовательную задачу. Многие из них освещают тематику совещаний государственной и местной администрации и принятые там решения, которые формально касались результатов осуществленных мероприятий и проблем 30Ж населения. Фактиче- ски действующими лицами этих публикаций являются представители властей и социальных институтов. Однако важно, что проблемы ЗОЖ находятся в их поле зрения, привлекают внимание к теме. 10,0\% публикаций - рекламные. Они заблаговременно сообщают о проводимых мероприятиях, имеющих отношение к 30ж - например, днях здоровья, забегах, зарядках с чемпионом, велопробегах, приглашая принять в них участие.Доля мотивирующих к ЗОЖ (16\%) и просветительских о ценностях 30Ж публикаций $(20,1 \%)$ в сумме составляет лишь треть всех публикаций, но это значительный вклад в продвижение идей и ценностей 3ОЖ для читателей газет. Мы полагаем, что баланс публикаций должен быть смещен в пользу этой группы.

Тематика публикаций отражает представленность в общей повестке тех или иных компонентов ЗОЖ, среди которых рассматриваются как непосредственные элементы образа жизни, так и соотнесенность с различными общественными сферами (см. табл. 2).

Таблица 2. Тематические предпочтения

\begin{tabular}{|c|l|c|c|}
\hline № & \multicolumn{1}{|c|}{ Тематика } & Количество & \% \\
\hline 1 & Политика & 55 & 9,4 \\
\hline 2 & Зарубежный опыт & 19 & 3,2 \\
\hline 3 & Культура & 22 & 3,7 \\
\hline 4 & $\begin{array}{l}\text { Профилактика } \\
\text { здоровья }\end{array}$ & 94 & 16,0 \\
\hline 5 & Личности & 7 & 1,2 \\
\hline 6 & $\begin{array}{l}\text { Медицина, } \\
\text { психология }\end{array}$ & 61 & 10,4 \\
\hline 7 & Мероприятия & 201 & 34,2 \\
\hline 8 & Питание & 36 & 6,1 \\
\hline 9 & $\begin{array}{l}\text { Быт, среда, семья, } \\
\text { ценности }\end{array}$ & 56 & 9,5 \\
\hline 10 & Спорт & 31 & 5,3 \\
\hline 11 & Другое & 5 & 1 \\
\hline \multicolumn{2}{|c|}{ Итого } & 587 & 100 \\
\hline
\end{tabular}

Анализ тематики публикаций привел к следующим наблюдениям и обобщениям. 
Представители властных структур озабочены неблагоприятным состоянием здоровья населения, ими осознается необходимость широкого распространения практики ЗОЖ, в том числе в подростковой среде. Например: «В администрации области прошло заседание координационного совета, ключевым вопросом которого стала популяризация здорового образа жизни в подростковой среде. Совещание провела вице-губернатор Оксана Лобода. Образовательные организации, отмечалось в ходе заседания, являются ключевым звеном в формировании здорового образа жизни и популяризации спорта и физической культуры среди детей и подростков» 9 . Перспективна инициатива министерства финансов: «Вернуть часть денег, потраченных на занятия спортом, смогут вскоре работающие россияне. Министерство финансов приступило к разработке документа, предусматривающего возможность соответствующего налогового вычета. Таким образом, федеральные власти намерены подвигнуть граждан на ведение активного образа жизни и систематические занятия спортом»10.

Особое внимание привлечено к продолжительности жизни работающих мужчин. «Губернатор Тульской области Алексей Дюмин поручил региональным министрам обратить особое внимание именно на укрепление здоровья мужской части населения. Результатом стала разработка специальной программы по сохранению и укреплению мужского здоровья, разработанная под руководством заместителя председателя регионального правительства Марины Левиной. В программу вошли традиционные мероприятия по раннему выявлению и лечению заболеваний и социальной пропаганды здорового образа жизни»11.

Повседневная и долгосрочная работа по продвижению 30Ж часто подменяется разовыми, звучными, плакатными, поста- новочными акциями и мероприятиями (об этом и подавляющее число публикаций 34,2\%). «27 мая 2018 года одновременно в 54 городах России состоится VII Национальный забег "Зеленый марафон". "Зеленый марафон" - это мероприятие, направленное на продвижение массового спорта и здорового образа жизни. Мероприятие проводится в крупнейших городах России - в предыдущие годы его участниками стали более 300 тысяч человек»12. Это праздничные акции; дни здоровья, когда раз в году в парке ставят палатку, где можно измерить давление; зарядка с чемпионом, когда приезжает олимпийский чемпион и в парке проводит зарядку для желающих: «Зарядка с чемпионом собрала более сотни юных конькобежцев на стадионе "Витязь" в Вологде. На коньки вместе с олимпийским чемпионом, начальником областного Департамента физической культуры и спорта Сергеем Фокичевым встали школьники и студенты, юные спортсмены, активисты ОНФ и все, кто любит кататься на коньках. Акцией "Зарядка с чемпионом" был открыт зимний спортивный сезон на стадионе "Витязь"»13; забег или заезд в честь кого-либо или чего-либо; одноразовые беседы в школе с учениками о вреде наркотиков. Исполнительные власти отчитываются депутатам Думы о количестве мероприятий и участников. Руководство страны уверено, что намеченная социальная политика государства реализуется. Такие мероприятия, безусловно, важны; в совокупности они оказывают влияние на продвижение ценностей, но не могут заменить менее заметную, но чрезвычайно важную повседневную информацию.

О настоящей кропотливой, долгосрочной работе по формированию ценностей ЗОЖ среди населения, особенно среди детей и молодежи, публикаций мало. На наш взгляд, это свидетельствует о том, что эти события не становятся инфоповодом для газет, и журналисты не могут пока найти 
Таблица 3. Жанровые особенности

\begin{tabular}{|c|c|c|c|}
\hline № & Жанр & Количество & $\%$ \\
\hline 1 & $\begin{array}{l}\text { Краткая } \\
\text { новость }\end{array}$ & 167 & 28,4 \\
\hline 2 & $\begin{array}{l}\text { Расширенная } \\
\text { новость }\end{array}$ & 227 & 38,8 \\
\hline 3 & Репортаж & 41 & 7 \\
\hline 4 & Статья & 40 & 6,8 \\
\hline 5 & Просвещение & 22 & 3,7 \\
\hline 6 & Обозрение & 34 & 5,8 \\
\hline 7 & Интервью & 29 & 4,9 \\
\hline 8 & Очерк & 17 & 2,9 \\
\hline 9 & $\begin{array}{l}\text { Журналистское } \\
\text { расследование }\end{array}$ & 6 & 1 \\
\hline 10 & Другое & 4 & 0,7 \\
\hline \multicolumn{2}{|r|}{ Итого } & 587 & 100 \\
\hline
\end{tabular}

формы подачи предъявления такой нужной информации.

Профилактике здоровья посвящены 16,0\% публикаций. Строятся новые спортивные комплексы, куда приглашаются не только спортсмены, но также дети и пенсионеры, строятся дворовые площадки со спортивными снарядами для населения, в городах организуются безопасные велосипедные дорожки. Публикуются советы по правильным физическим упражнениям и питанию.

У известных спортсменов, выдающихся личностей, долгожителей редко берут интервью об их опыте 30Ж (всего 1,2\% публикаций). Недостаточно освещается и ценный зарубежный опыт (3,2\% публикаций).

Анализ тематики публикаций показывает, что основные направления продвижения 30Ж в газетах представлены, однако, как и в предыдущей категории, наблюдается их несбалансированность, потенциально ослабляющая эффективность продвижения столь необходимой для аудитории информации.

Жанры публикаций отражают степень погружения в те или иные явления, проб-
Таблица 4. Субъекты мнений

\begin{tabular}{|c|l|c|c|}
\hline № & \multicolumn{1}{|c|}{ Мнение } & Количество & \% \\
\hline 1 & Журналиста & 289 & 49,3 \\
\hline 2 & Медика & 89 & 15,2 \\
\hline 3 & Спортсмена & 27 & 4,6 \\
\hline 4 & Чиновника & 114 & 19,4 \\
\hline 5 & Кулинара & 22 & 3,7 \\
\hline 6 & Психолога & 17 & 2,9 \\
\hline 7 & Читателя & 23 & 3,9 \\
\hline 8 & Другое & 6 & 1 \\
\hline \multicolumn{2}{|c|}{ Итого } & 587 & 100 \\
\hline
\end{tabular}

лемы, обстоятельства, а также коммуникативные намерения авторов текстов, отражающие, по сути, цели обращения к конкретным реалиям (см. табл. 3). Репортажи, статьи, интервью, обозрения, очерки, образовательные статьи составляют 32,8\% всего объема публикаций. Они очень интересны и ценны - реально обсуждают и приглашают задуматься над ценностями 30ж. 28,4\% публикаций - это краткая новость, 38,8\% всех публикаций - расширенная новость, т.е. 67,2\% публикаций можно отнести к продвижению 30Ж лишь формально; ценности здоровья при этом лишь подразумеваются, а оснований для реального приближения к здоровой жизни предоставлено недостаточно.

Категория анализа «Субъекты мнений» дает возможность оценить авторитетность и достоверность предоставленной информации, качество проведенной экспертной оценки (см. табл. 4). В массовой прессе можно встретить мнение чиновников высокого ранга: «Глава Минздрава Вероника Скворцова сообщила, что за последние несколько лет в России почти вдвое сократилось потребление алкоголя и до- 
стигло в 2018 году 9,3 литра на человека (в 2011 году - 18 литров). По словам министра, результата удалось достичь в том числе благодаря реализации разработанных ведомством инициатив по снижению доступности алкоголя и популяризации здорового образа жизни»14.

Подавляющее большинство субъектов мнений - это журналисты (49,3\%), т.е. люди, являющиеся специалистами в журналистике, но не экспертами в области ЗОЖ. Это существенно снижает авторитетность представленной и обсуждаемой информации, обоснованность высказанных комментариев. 19,4\% субъектов мнений - чиновники, которые также не являются экспертами 30ж, но в силу наложенных на них обязанностей вынуждены вникать в данный круг проблем. Нередко их мнение играет формальную роль для необходимой отчетности. Ценные советы и мнения реальных специалистов в области ЗОЖ - медиков, психологов, педагогов в общем объеме публикаций представлены в 21,8\% публикаций. Эта доля может быть увеличена.

Аргументация - это особенности воздействия на адресата, направленные на обоснование какого-либо утверждения; категория анализа «Характер аргументации» отражает способ этого обоснования в анализируемых публикациях (см. табл. 5).

В текстах, продвигающих идеологию 30ж, большинство аргументов - 53,8\% рациональные, которые и являются самыми убедительными: «Я призываю всех включиться в акцию "Зарядка с чемпионом", потому что здоровье - это ценность каждого человека и приоритет в политике нашего государства. Будем создавать хорошее настроение! Мы работаем ради молодежи, детей, которые должны быть сильными и здоровыми», - отмечает олимпийский чемпион Сергей Фокичев ${ }^{15}$. В 39,6\% публикаций, в первую очередь информационных, аргументация в пользу 30ж на уровне текстовых элементов не представлена, она
Таблица 5. Характер аргументации

\begin{tabular}{|c|l|c|c|}
\hline № & \multicolumn{1}{|c|}{ Аргументы } & Количество & \% \\
\hline 1 & $\begin{array}{l}\text { Рациональные } \\
\text { аргументы }\end{array}$ & 316 & 53,8 \\
\hline 2 & $\begin{array}{l}\text { Эмоциональные } \\
\text { аргументы }\end{array}$ & 39 & 6,6 \\
\hline 3 & $\begin{array}{l}\text { Аргументация } \\
\text { отсутствует }\end{array}$ & 232 & 39,6 \\
\hline \multicolumn{2}{|l|}{ Итого } & 587 & 100 \\
\hline
\end{tabular}

лишь подразумевается: «Благотворительный проект организован с целью популяризации бега на сверхдлинные дистанции за 14 дней участники забега преодолеют более 800 километров. Помимо пропаганды здорового образа жизни и приобщения людей к бегу организаторы ставят перед собой важнейшую задачу - привлечение внимания к детям с синдромом Дауна»16.

\section{Здоровье, СМИ, аудитория: ресурсный потенциал}

Проведенный контент-анализ полностью подтвердил справедливость утверждения исследователя гуманитарной медиаповестки Т.И. Фроловой (2009: 10) о том, что «прессе пока не удалось сформировать представление о здоровье как абсолютной ценности и победить приверженность россиян традиционно нездоровым моделям поведения и вредным привычкам. Качество журналистики о здоровье в целом все чаще признается неэффективным, не раскрывшим все свои ресурсы и потенциальные возможности».

Существенные обобщения по результатам контент-анализа публикаций о 30Ж в массовой периодической печати свидетельствуют о том, что тема здоровья как одна из главных экзистенциальных ценностей популярна у аудитории. Публикации размещаются практически в каждом номере. Они разнообразны по направленности, тематике, жанровым решениям. Однако использованы далеко не все медийные 
ресурсы. Массовые СМИ в силу своей типологической принадлежности являются хорошим каналом для продвижения ценностей здорового образа жизни, играющего основную роль в повышении качества жизни россиян, увеличения продолжительности жизни, укреплении человеческого потенциала общества. Проведенный анализ показывает, что основные просчеты, на которые необходимо обратить внимание журналистам, состоят в следующем:

1. В поле зрения журналистов в первую очередь попадают постановочные, плакатные события, акции (34,2\%), но ускользает неброская повседневная работа по продвижению ценностей 30ж.

2. Массовая периодическая печать дает читателям слишком мало вдохновляющих примеров 30Ж известных, авторитетных людей и ценного зарубежного опыта. Мотивирующий опыт этим ослабляется.

3. Публикации непропорционально отражают соотношение различного рода реальной работы политиков, медиков, спортсменов, психологов, педагогов и самих журналистов по продвижению ценностей
30Ж в обществе. Более того, они порой создают искаженное представление о фактическом положении дел. Это следствие специфики функционирования печатного СМИ, издательскую политику которого определяет владелец, социально-экономическая и политическая ситуация в стране, законы капиталистического рынка.

Таким образом, анализ массовой периодической печати России с целью выявления используемых ею методов продвижения ценностей здорового образа жизни и определения степени соответствия используемых практик объективным потребностям человека и общества в сохранении и укреплении здоровья населения показал, что качество и содержание публикаций соответствует потребностям аудитории. Однако в практиках массовых изданий еще достаточно ресурсов, которые могут быть использованы для решения задач по вовлечению широких масс населения в здоровьесберегающие практики повседневности и, как следствие, для повышения общего качества и продолжительности жизни россиян.

\section{Примечания}

${ }^{1}$ Европейский портал информации здравоохранения. Режим доступа: https:// gateway.euro.who.int/ru/

2 Росстат. Ожидаемая продолжительность жизни при рождении. Режим доступа: http://www.gks.ru/free_doc/new_site/population/demo/progn7.htm

3 Human Development Indices and Indicators. Режим доступа: http://hdr.undp.org/ sites/default/files/2018_human_development_statistical_update.pdf

4 Паспорт национального проекта «Демография». Режим доступа: http:// government.ru/info/35559/

5 Стратегия формирования здорового образа жизни населения, профилактики и контроля неинфекционных заболеваний на период до 2025 года. Режим доступа: https://www.gnicpm.ru/UserFiles/stragedy_project_fin_2512.pdf

6 Всемирная организация здравоохранения о здоровом образе жизни. Режим доступа: http://ippk.arkh-edu.ru/doc/detail.php?ID=832574

7 Скворцова назвала причину большинства смертей российских мужчин // MK.ru. 2019. Март, 23. Режим доступа: https://www.mk.ru/social/health/2019/03/23/ skvorcova-nazvala-prichinu-bolshinstva-smertey-rossiyskikh-muzhchin.html 
8 Добрынина Е. За наше нездоровье // Рос. газета. 2011. Апр., 22. Режим доступа: https://rg.ru/201l/04/21/zdorovie.html

9 В Смоленске обсудили, как привить детям 30ж // MK.ru. . 2018. Июль, 26. Режим доступа: https://www.mk-smolensk.ru/social/2018/07/26/v-smolenske-obsudili-kakprivit-detyam-zozh.html

10 Минфин предложит россиянам налоговый вычет за занятия спортом // MK.ru. 2019. Янв., 22. Режим доступа: https://www.mk.ru/economics/2019/01/22/minfinpredlozhit-rossiyanam-nalogovyy-vychet-za-zanyatiya-fitnesom.html

11 Общественники в Тульской области задумались над мужским здоровьем // MK.ru. 2018. Сент., 28. Режим доступа: https://tula.mk.ru/social/2018/09/28/ obshhestvenniki-v-tulskoy-oblasti-zadumalis-nad-muzhskim-zdorovem.html

12 В 54 городах России состоится национальный забег «Зеленый марафон» // MK. ru. Саратов. 2018. Май, 16. Режим доступа: https://saratov.mk.ru/social/2018/05/16/ v-54-gorodakh-rossii-sostoitsya-nacionalnyy-zabeg-zelenyy-marafon.html

13 Вологодские активисты ОНФ организовали «Зарядку с чемпионом» // MK.ru. Вологда. 2018. Дек., 4. Режим доступа: https://vologda.mk.ru/social/2018/12/04/ vologodskie-aktivisty-onf-organizovali-zaryadku-s-chempionom.html

14 Минздрав: россияне стали вдвое меньше пить // MK.ru. 2019. Апр., 24. Режим доступа: https://www.mk.ru/social/2019/04/24/minzdrav-rossiyane-stali-vdvoemenshe-pit.html

15 Вологодские активисты ОНФ организовали «Зарядку с чемпионом» // MK. ru. Вологда. 2018. Дек., 4. Режим доступа: https://vologda.mk.ru/social/2018/12/04/ vologodskie-aktivisty-onf-organizovali-zaryadku-s-chempionom.html

16 Через Смоленск пройдет благотворительный забег «Соединяя Столицы...» // MK. ru. Смоленск. 2018. Авг., 21. Режим доступа: https://www.mk-smolensk.ru/ sport/2018/08/21/cherez-smolensk-proydyot-blagotvoritelnyy-zabeg-soedinyayastolicy.html

\section{Библиография}

Афанасьева В.В., Воробьев Р.В. Онтология здоровья. Саратов: Науч. кн., 2013.

Бриленок Н.Б. Здоровый образ жизни как социальная практика // Изв. Саратовск. ун-та. Новая серия. Философия. Психология. Педагогика. 2016. Вып. 1. Т. 16. С. 5-9.

Быховская И.М. Здоровье как практическая аксиология тела // Мир психологии. 2000. № 1 (21). С. 82-89.

Гавриченкова Е.А. Роль средств массовой информации в формировании здорового образа жизни // Молодой ученый. 2018. № 18. С. 157-161.

Гиппократ. О здоровом образе жизни // Наставления. Минск: Современный литератор, 1998. С. 111-139.

Гурвич И.Н. Социальная психология здоровья: дис. .... д-ра психол. наук. СПб, 1997.

Калина М.С. Здоровый образ жизни в информационную эпоху: между ценностью и модой // Науч.-спорт. вестн. Урала и Сибири. 2014. № 2. С. 47-50.

Лисицын Ю.П., Сахно А.В. Здоровье человека - социальная ценность. М.: Мысль, 2008.

Магидов С.Х. Идеология здорового образа жизни и глобальная стратегия развития // Здоровье и образование в XXI веке. 2010. № 9. Т. 12. С. 446-448. 
Пилипцев Н.Н., Часнойть Р.А., Павлович Т.П. Здоровый образ жизни - ведущий фактор, обусловливающий здоровье // Вопросы организации и информатизации здравоохранения. 2016. № 2. С. 55-61.

Рагимова О.А. Историко-философская ретроспектива представлений о здоровье // Философия здоровья. Саратов: Изд-во Саратовск. гос. ун-та, 2012. С. 15-23.

Розин В.М. Здоровье как философская и социально-психологическая проблема // Кентавр. 2000. № 22. С. 36-44.

Сорокина В.М., Сорокин Д.Ю. Формирование отношения к здоровому образу жизни как ценности // Современные проблемы науки и образования. 2009. № 5. С. 39-42.

Страхова И.Б. Здоровый образ жизни как способ интеграции в социум (на примере студентов с ослабленным здоровьем): дис. ... канд. социол. наук. Новосибирск, 2005.

Стрига Е.А. Продвижение ценностей здорового образа жизни в российской прессе: исследовательские перспективы // Социально-гуманитарные знания. 2018. № 12. С. 158-166.

Типология периодической печати / под ред. М.В. Шкондина, Л.Л. Реснянской. М.: Аспект Пресс, 2009.

Фролова Т.И. Гуманитарная повестка российских СМИ. Журналистика, человек, общество. М.: МедиаМир, 2014.

Фролова Т.И. Здоровье, журналистика и образование: стратегии эффективности // Журналистика для здоровья нации. М.: МедиаМир, 2009. С. 3-16. 